\title{
Artigos em inglês nos Arquivos Brasileiros de Oftalmologia: um resultado da globalização
}

\author{
Cristina Muccioli, Mauro Campos, Mauro Goldchmit, Paulo E. C. Dantas, Samir J. Bechara, Vital Paulino Costa
}

\begin{abstract}
A indexação dos Arquivos Brasileiros de Oftalmologia no PubMed foi uma conquista de toda a comunidade oftalmológica nacional, resultado de um trabalho árduo e intenso, que possibilitou o acesso de oftalmologistas de todo mundo aos artigos publicados por colegas brasileiros. Desde a indexação, observamos um aumento significativo de manuscritos submetidos em inglês, fazendo com que o número de artigos publicados nesse idioma subisse de 15 no ano passado para cerca de 30 (estimativa) em 2006. Este fato motivou observações como a feita pelo Dr. Celso Chaves, em e-mail publicado na Sessão Carta ao Editor.

Embora seja compreensível a preocupação deste e de outros colegas, que questionam o excesso de artigos publicados num idioma diferente de nossa língua-mãe, podendo comprometer a compreensão destes artigos por parte da comunidade oftalmológica brasileira, vale lembrar que, há 35 anos, as Instruções para Autores permitem a submissão de artigos em inglês. Em outras palavras, os Arquivos Brasileiros de Oftalmologia desde há muito valorizam a contribuição de artigos escritos em outro idioma, inicialmente como forma de atrair artigos internacionais para publicação. Vale enfatizar que a escolha do idioma da publicação é opção dos autores e não do Conselho Editorial dos Arquivos.

A partir do momento que os artigos publicados nos Arquivos passaram a ser acessíveis a médicos de todo o mundo, a possibilidade de publicar em outros idiomas não somente atrai autores de outros países, como também estimula autores na-
\end{abstract}

cionais a publicar artigos em inglês, facilitando sua compreensão por oftalmologistas espalhados mundo afora.

Até que ponto estes colegas brasileiros que decidem publicar em inglês podem ser criticados? De um lado, não há como criticar autores que desejam ter o seu trabalho difundido e reconhecido internacionalmente, sobretudo num mundo globalizado, em que o acesso online permite que um artigo seja lido na íntegra em minutos. Por outro lado, suspeita-se que há artigos que são submetidos em inglês após serem recusados por outras revistas internacionais. Nesse caso, os Arquivos Brasileiros de Oftalmologia não figurariam como primeira opção para a difusão do trabalho nacional. Se isto de fato ocorrer, supõe-se que a justificativa seja a de que outras revistas possuem maior fator de impacto e, portanto, possibilitariam maior exposição do artigo em questão.

É essa explicação que nos preocupa, pois cria um ciclo vicioso. Ao enviar artigos primeiramente a outras revistas de maior fator de impacto, reduzem-se progressivamente as chances de gerar impacto nos nossos Arquivos. Os Arquivos Brasileiros de Oftalmologia são o principal veículo de difusão da produção científica da comunidade oftalmológica brasileira para o mundo. Como tal, conclamamos os autores nacionais que desejam publicar artigos em inglês a enviá-los preferencialmente aos Arquivos Brasileiros de Oftalmologia. Acreditamos que o aumento do número de artigos publicados em inglês seja uma realidade necessária, que tende a aumentar nos próximos anos e que contribui para a divulgação do alto nível da oftalmologia de nosso país. 